ORIGINAL ARTICLE

\title{
Comparison of two methods of presenting risk information to patients about the side effects of medicines
}

\section{P Knapp, D K Raynor, D C Berry}

See editorial commentary, p 169

Qual Saf Health Care 2004;13:176-180. doi: 10.1136/qshc.2003.009076

See end of article for authors' affiliations ......................

Correspondence to: Dr P Knapp, Pharmacy Practice \& Medicines Management Group, University of Leeds, Leeds LS2 9JT, UK; p.r.knapp@leeds.ac.uk

Accepted for publication 17 April 2004
Objective: To determine whether the use of verbal descriptors suggested by the European Union (EU) such as "common" (1-10\% frequency) and "rare" $(0.01-0.1 \%)$ effectively conveys the level of risk of side effects to people taking a medicine.

Design: Randomised controlled study with unconcealed allocation.

Participants: 120 adults taking simvastatin or atorvastatin after cardiac surgery or myocardial infarction. Setting: Cardiac rehabilitation clinics at two hospitals in Leeds, UK.

Intervention: A written statement about one of the side effects of the medicine (either constipation or pancreatitis). Within each side effect condition half the patients were given the information in verbal form and half in numerical form (for constipation, "common" or $2.5 \%$; for pancreatitis, "rare" or $0.04 \%$ ).

Main outcome measure: The estimated likelihood of the side effect occurring. Other outcome measures related to the perceived severity of the side effect, its risk to health, and its effect on decisions about whether to take the medicine.

Results: The mean likelihood estimate given for the constipation side effect was $34.2 \%$ in the verbal group and $8.1 \%$ in the numerical group; for pancreatitis it was $18 \%$ in the verbal group and $2.1 \%$ in the numerical group. The verbal descriptors were associated with more negative perceptions of the medicine than their equivalent numerical descriptors.

Conclusions: Patients want and need understandable information about medicines and their risks and benefits. This is essential if they are to become partners in medicine taking. The use of verbal descriptors to improve the level of information about side effect risk leads to overestimation of the level of harm and may lead patients to make inappropriate decisions about whether or not they take the medicine.
1 nforming people effectively about the risk of side effects from their medicines is essential if they are to be able to make informed decisions about their medicine taking. Research suggests that information about side effects is the highest information priority for patients, and that the perception of side effects is influential in many patients' decisions about taking a medicine. ${ }^{12}$ The greater involvement of patients in decisions about their treatment-which lies at the heart of the concordance initiative ${ }^{3}$ and is endorsed in the National Plan for the $\mathrm{NHS}^{4}$-is predicated on the patient having access to understandable information.

The information on side effects currently provided to people taking medicines is largely limited to a straightforward list in the package insert leaflet. Such leaflets are now required by European Union (EU) legislation to be included in every medicine pack, ${ }^{5}$ but currently little information is given about the probability of each side effect occurring. In 1999 the EU produced a guideline on the readability of leaflets ${ }^{6}$ which indicated that the frequency of side effects could be denoted by the use of five verbal descriptors ("very common", "common", "uncommon", "rare", "very rare") as an alternative to numerical incident rates. Each of the verbal terms is linked to a particular numerical rate (box l).

In common with a previously developed verbal risk scale, the EU guideline appeared not to be evidence based and, at face value, the terms used appeared unlikely to be interpreted as corresponding to the chosen percentage risk bandings. In addition, previous work has shown large individual differences in the interpretation of such verbal terms. ${ }^{89}$

As a result, we previously conducted a series of studies to test the interpretation of the five verbal terms by members of the public when compared with the numerical equivalents. ${ }^{10} 11$ In an analogue study using a scenario of having a sore throat and visiting a doctor who prescribed an antibiotic, we showed that the verbal terms led to a gross overestimation of risk, particularly of the less frequent side effects. People who received the risk information using the verbal descriptors also saw the side effects as more severe, thought they posed a greater risk to health, were less satisfied with the information, and said they would be less likely to take the medicine.

It is not clear whether risk perception in the clinical situation shows the same patterns as those found in nonclinical studies. ${ }^{12}$ The present study therefore examines the verbal descriptors and their numerical equivalents in a clinical situation where people are taking medicines for a chronic condition. We compared the effects of two of the EU verbal terms ("common" and "rare") with their numerical equivalents in information about statins. We limited the study to two of the five terms to ensure that the study was adequately powered. Furthermore, reliable incident rates were not available for side effects in all five frequency categories for the chosen statin medicines.

\section{METHODS \\ Participants and setting}

120 adults attending cardiac rehabilitation clinics at two Leeds hospitals following a recent admission for coronary artery bypass surgery or myocardial infarction who were taking either simvastatin or atorvastatin were recruited to the study. Those who could not read or whose first language was not English were excluded. Forty five patients attending the clinic who were eligible for the study declined to participate.

\section{Design and procedure}

A randomised controlled method was used with two independent between subject variables: format of information 
Box 1 European Union verbal descriptors of side effect probability and allocated frequencies

- Very common: $>10 \%$

- Common: $1-10 \%$

- Uncommon: 0.1-1\%

- Rare: 0.01-0.1\%

- Very rare: $<0.01 \%$

\section{Box 2 Information given to participants}

- This study is investigating the information given to you about your prescribed medicine atorvastatin.

- Please read the information below about atorvastatin. Then answer the questions that follow.

- You can re-read the information about atorvastatin when answering the questions.

- I am interested in your immediate responses-please do not spend too long thinking about your answers to the questions.

(numerical or verbal) and side effect (constipation or pancreatitis). The allocation order was randomly predetermined and the questionnaires stored in order before use. The allocation order was not concealed but only after participant recruitment did the researcher take the next questionnaire from the pack.

After giving their written consent to take part in a study of "different ways of giving patients information about their medicines", participants were asked to read a short piece of information about a side effect associated with the medicine they were taking (box 2). Half the participants received information about constipation, a frequently occurring mild side effect (both medicines); the rate of $2.5 \%$ was taken from the $4 \mathrm{~S}$ trial (simvastatin) ${ }^{13}$ and a systematic review of trials of atorvastatin. ${ }^{14}$ The other half were given information about pancreatitis, a less frequent and more severe side effect (those taking atorvastatin only) with an incident rate of $0.04 \% .{ }^{14}$ Within each side effect, half the participants received the information in a numerical form ("This side effect occurs in $0.04 \%$ (that is, 4 out of 10 000) people who take this medicine") and half in a verbal form ("This is a rare side effect of the medicine")

After reading the risk information, participants completed the answer sheet. They could refer back to the risk information when answering the questions. Participants were asked to give a percentage probability of the likelihood of having the side effect. They were also asked to respond to five questions on Likert scales (range 1-6) about the overall likelihood of their experiencing a side effect, their perception of the risk to their health, the severity of the side effect, their satisfaction with the information and, whether the information would affect their decision to take the medicine. The full information given and the questions are shown in box 2 .

\section{Analysis of data}

The main outcome measure was the estimate of the likelihood of the side effect occurring. Secondary measures related to Likert scale responses to the five additional questions. The data were analysed using independent $t$ tests after ensuring approximately normal distributions. The sample size of 30 in each of the four groups (verbal/numerical and constipation/pancreatitis) was calculated using data from our previous scenario based studies. The sample size had $90 \%$ power to detect a difference at the $5 \%$ significance level in the estimated probability of side effect occurrence. The study was approved by the local NHS research ethics committee.

\section{RESULTS}

One hundred and twenty patients were recruited ( 76 men) of median age 63 years (range 35-74) who had been taking a statin for a median of 6 months (range 1-70). They came from a range of educational backgrounds although the majority ( $n=67,56 \%$ ) had no formal educational qualifications. The patients recruited to each of the four groups were comparable with respect to demographic data (table 1).
"Atorvastatin is associated with some side effects. It can cause pancreatitis. This is a rare side effect of the medicine." (Verbal condition only)

"Atorvastatin is associated with some side effects. It can cause pancreatitis. This side effect occurs in $0.04 \%$ (that is, 4 in 10 000) people who take this medicine." (Numerical condition only)

\section{Questions given to all participants}

- Overall, how satisfied are you with the information you have just read about the side effects of atorvastatin? Measured on a 6 point scale ranging from 1 (not at all satisfied) to 6 (very satisfied).

- Bearing in mind the information you have just read, how severe is the given side effect of atorvastatin? Measured on a 6 point scale ranging from 1 (not at all severe) to 6 (very severe).

- From the information you have just read, how likely is it that YOU would experience this side effect from taking atorvastatin? Measured on a 6 point scale ranging from 1 (not at all likely) to 6 (very likely).

- What do you think is the probability that YOU will experience this side effect from taking atorvastatin? Please state your answer as a percentage.

- Bearing in mind the side effect information you have just read, what do you think is the general risk to your health from taking atorvastatin? Measured on a 6 point scale ranging from 1 (no risk at all) to 6 (very high risk).

- How much will the side effect information you have just read influence your decision to keep taking atorvastatin? Measured on a 6 point scale ranging from 1 (definitely will not) to 6 (definitely will).

\section{Pancreatitis ("rare" versus $0.04 \%$ )}

The mean estimate of the likelihood of having pancreatitis was $18.0 \%$ in the verbal group and $2.1 \%$ in the numerical group $(\mathrm{p}<0.001$, table 2$)$. Participants in the verbal group also thought they were more likely to experience a side effect $(p=0.006)$ and thought that the side effect would pose a greater risk to their health $(\mathrm{p}=0.002)$. The two groups showed no statistically significant difference in their rating of the severity of the side effect $(p=0.20)$. Participants in the verbal group were less satisfied with the information provided $(\mathrm{p}=0.048)$, but there was no difference between the groups in their rating of whether the information would affect their decision to take the medicine $(p=0.16)$.

\section{Constipation ("common"' versus $2.5 \%$ )}

The mean estimate of the percentage of people who would experience constipation was $34.2 \%$ in the verbal group and $8.1 \%$ in the numerical group $(\mathrm{p}<0.001$, table 3$)$. Participants in the verbal group also thought they would be more likely to 


\begin{tabular}{|c|c|c|c|c|}
\hline \multirow[b]{2}{*}{ Characteristic } & \multicolumn{2}{|c|}{ Pancreatitis } & \multicolumn{2}{|c|}{ Constipation } \\
\hline & Verbal & Numerical & Verbal & Numerical \\
\hline $\operatorname{Sex}(M: F)$ & $16: 14$ & $18: 12$ & $21: 9$ & $21: 9$ \\
\hline \multicolumn{5}{|l|}{ Age } \\
\hline$<60$ & 9 & 12 & 7 & 11 \\
\hline $60-69$ & 16 & 15 & 16 & 12 \\
\hline $70+$ & 5 & 3 & 7 & 7 \\
\hline \multicolumn{5}{|l|}{ Education } \\
\hline None & 17 & 16 & 18 & 16 \\
\hline \multicolumn{5}{|l|}{ Qualification } \\
\hline O level & 9 & 8 & 10 & 9 \\
\hline A level or higher & 3 & 6 & 2 & 5 \\
\hline Mean (SD) months taking statin & $11(13.4)$ & $12(16.1)$ & $19(28.3)$ & $16(29.8)$ \\
\hline
\end{tabular}

experience a side effect $(\mathrm{p}<0.001)$ and that the constipation would pose a greater risk to their health $(p=0.041)$. The two groups showed no statistically significant difference in their rating of its severity $(p=0.39)$. Participants in the verbal group were more likely to say that the information would affect their decision to take the medicine $(p=0.037)$, but there was no difference between the groups in their satisfaction with the information provided $(p=0.06)$.

\section{DISCUSSION}

The principal findings are that participants given verbal terms to describe the likelihood of side effects of medicines they were taking thought those effects would be far more frequent than people given the numerical percentage equivalents. In the case of the term "common" (suggested by the EU for incident rates of $1-10 \%)$, the probability of the side effect occurring was said to be $34 \%$-more than three times the upper end of the designated frequency band. The term "rare" (intended for incidences of $0.01-0.1 \%$ ) was interpreted as having a probability of almost $20 \%-18$ times the upper end of the frequency band.

This is the first study to examine this effect in the clinical setting - that is, ascribing these verbal terms to side effects for medicines which the participants were taking. Our previous scenario-based studies found mean estimates in the range $45-56.6 \%$ for "common" and $6.3-21.5 \%$ for "rare". ${ }^{10}$ Thus, the patients taking real medicines followed the same pattern with a greater degree of overestimation for the less frequent (and much more serious) side effect. This lends further weight to the conclusion that use of the verbal terms in the EU guideline leads to a gross overestimation of the probability of harm. Our results are in agreement with earlier Dutch and German studies which showed that verbal terms are not always interpreted in the way intended. ${ }^{15} 16$
Participants who received the verbal descriptors of risk thought they would be more likely to suffer side effects themselves, with ratings some $40-60 \%$ higher than in the numerical group. The verbal descriptors also resulted in greater perceived risk to health from the medicine, with ratings $40 \%$ higher than in the numerical group. Verbal descriptors led to participants being generally less satisfied with the information provided (one statistically significant difference and one borderline difference).

The provision of side effect risk information using the verbal descriptors also showed potential effects on the decision to take the medicine. This may be the most important aspect, since it indicates a possible change in the patient's behaviour in medicine taking rather than simply a difference in perception about the safety of the medicine. Patients given the verbal information about the constipation side effect were significantly more likely to say that it would affect their decision to take the medicine. Patients given similar information about pancreatitis showed a similar trend but this did not reach statistical significance.

One limitation of the study is that the patients had been taking the medicines for variable periods, in some cases for many months. They are likely to have based their responses on personal experience as well as on the information provided. Testing the verbal descriptors with people about to take a medicine for the first time would give further insight into the effects on perception of risk and willingness to take the medicine. It is also likely that those attending cardiac rehabilitation clinics are not typical of the population of patients taking these medicines.

Another limitation may be the method of group allocation as the researcher was potentially aware of the next allocation at the time of recruitment. A lack of allocation concealment can be associated with exaggerated group differences, but it is most likely to occur when the researcher can anticipate

\begin{tabular}{|c|c|c|c|c|c|}
\hline & $\begin{array}{l}\text { Verbal } \\
(\text { "rare") }\end{array}$ & $\begin{array}{l}\text { Numerical } \\
(" 0.04 \% ")\end{array}$ & $\begin{array}{l}95 \% \mathrm{Cl} \text { of } \\
\text { difference }\end{array}$ & $t$ value & $p$ value \\
\hline $\begin{array}{l}\text { Probability of occurrence (\%) } \\
\text { Likert scale variables } \\
\text { (possible scores 1-6) }\end{array}$ & 18.0 & 2.1 & 8.2 to 23.5 & 4.16 & $<0.001$ \\
\hline Likelihood of occurrence & 3.3 & 2.4 & 0.3 to 1.5 & 2.84 & 0.006 \\
\hline Perceived risk to health & 3.4 & 2.4 & 0.4 to 1.7 & 3.31 & 0.002 \\
\hline Satisfaction with information & 3.3 & 4.1 & 0.08 to 1.6 & 2.02 & 0.048 \\
\hline Severity of side effect & 3.7 & 3.3 & -0.2 to 1.1 & 1.30 & 0.198 \\
\hline $\begin{array}{l}\text { Effect on decision to take } \\
\text { medicine }\end{array}$ & 3.1 & 2.5 & -0.3 to 1.5 & 1.42 & 0.163 \\
\hline
\end{tabular}


Table 3 Constipation: probability estimates of adverse event occurring and mean ratings of Likert scale variables as a function of mode of presentation (verbal or numerical)

\begin{tabular}{|c|c|c|c|c|c|}
\hline & $\begin{array}{l}\text { Verbal } \\
\text { ('common") }\end{array}$ & $\begin{array}{l}\text { Numerical } \\
(" 2.5 \% ")\end{array}$ & $\begin{array}{l}95 \% \mathrm{Cl} \text { of } \\
\text { difference }\end{array}$ & $t$ value & $\mathrm{p}$ value \\
\hline $\begin{array}{l}\text { Probability of occurrence (\%) } \\
\text { Likert scale variables (possible } \\
\text { scores 1-6) }\end{array}$ & 34.2 & 8.1 & 15.1 to 37.0 & 4.78 & $<0.001$ \\
\hline Likelihood of occurrence & 4.2 & 2.6 & 0.7 to 2.4 & 3.80 & $<0.001$ \\
\hline Perceived risk to health & 3.2 & 2.3 & 0.4 to 1.8 & 2.08 & 0.041 \\
\hline Satisfaction with information & 3.4 & 4.2 & -0.3 to 1.6 & 1.92 & 0.059 \\
\hline Severity of side effect & 3.2 & 2.8 & -0.5 to 1.3 & 0.86 & 0.393 \\
\hline $\begin{array}{l}\text { Effect on decision to take } \\
\text { medicine }\end{array}$ & 3.8 & 2.6 & 0.7 to 2.2 & 2.14 & 0.037 \\
\hline
\end{tabular}

how the prospective participant will respond to any allocated intervention. There is only a limited possibility that lack of concealment introduced bias here, as the researcher is unlikely to have been able to anticipate the patient's response to verbal or numerical information about a side effect. Furthermore, the comparability of the groups is confirmed in table 1.

Some participants asked to estimate the frequency of the side effect pancreatitis may not have understood the term, although no participant asked what it was. The estimated severity of pancreatitis (table 2) was much greater than the estimated severity of constipation (table 3 ), suggesting that most participants had some understanding of it. However, it would be useful for further research to explore participants' understanding of any side effects being researched.

In addition, asking participants to make an estimate of low frequency incident rates (such as the rate of pancreatitis in this study) by using a percentage may predispose them to making estimates of at least $1 \%$. This would have the effect of producing larger mean estimates. We have examined this effect in previous studies ${ }^{17}$ and found that telling participants that they can make estimates of less than $1 \%$ had no significant effect. Furthermore, any measurement weakness in the study that might influence participants' estimates applies equally to the verbal and numerical groups.

It is clear that, although we have found deficiencies with verbal descriptors, numerical information also has problems with some people finding it difficult to discuss risk in terms of numbers. ${ }^{18} 19$ Indeed, verbal descriptors have some advantages ${ }^{20}$ including the ability to divide a long list of side effects into manageable sections (based on frequency of occurrence). Also, there is often uncertainty about the precise level of risk for each side effect, as incident rates tend to vary between trials and many trials are too small to calculate low frequency incident rates. Verbal terms can allow for such variation and uncertainty. One conclusion is that we should examine which descriptors are most stable and determine the approximate bands of risk associated with those descriptors by the public. This and the previous scenario-based work would suggest that the term "very common" might be used for side effects occurring in over $50 \%$ of the population and "common" for $10-50 \%$. However, much more research is needed before such recommendations could be implemented.

Calman proposed different verbal labels (including "high", "moderate" and "low") to describe the risk of side effects of medicines, ${ }^{7}$ and these terms also need testing in a clinical setting. Clearly, a significant problem in using any standardised scale applied to all patients is the variability in people's estimates of what a verbal descriptor (such as "common") means. The findings of this study, in line with others we have conducted with hypothetical scenarios, have revealed not only that the verbal terms are associated with overestimation, but also the high degrees of variation in estimates. Similarly, other studies have shown that estimates vary according to the context in which the term is interpreted. ${ }^{21}$

Progress might be possible through using appropriate combinations of verbal and numerical information or using graphical presentation methods. ${ }^{20} 22$ Such flexibility might be needed to meet the variety of individual preferences or need. ${ }^{23}$ However, the large number of different side effects listed for most medicines makes this problematic-for example, 17 for simvastatin and 26 for atorvastatin. This is particularly relevant when space is limited, such as on a medicine leaflet. In addition, presenting each side effect with a percentage frequency will result in a long list of percentages (some to three or four decimal places). This is likely to deter many patients from reading the information. The use of the terminology " $x$ in 100000 " is another option. However, we found that the wordings recommended by the Committee on Safety of Medicines on the risk of thromboembolism with oral contraceptives (which used this terminology) were fully understood by less than one in eight women in higher education. ${ }^{24}$ Another possibility is to use scales based on community risk-for example, one person in your street, town, etc ${ }^{25} 26$-but again these would need testing in a clinical setting.

We conclude that, regardless of the impact on behaviour, the basic requirement that patients have a true understanding of the level of risk of side effects is far from being met. An accurate understanding of the likelihood of benefit and harm is fundamental to the concept of partnership in medicine taking, but we are some way from a standardised language of risk. ${ }^{25}$ The problems associated with communicating information about risk and uncertainty related to complex medical information are significant. A lack of shared understanding of risk frequencies between patient and practitioner (whatever method of information provision is used) reduces the possibility of informed patient participation in decisions about treatments. Furthermore, it reduces the quality of information that practitioners provide, since information that is misunderstood is of little use to patients. Indeed, misunderstanding information (by exaggerating the risk of a negative outcome, for example) might cause a patient to decide not to take a medicine which they might otherwise have taken if the information had been more usable. Until there is further research into people's interpretation of methods of describing the risk of side effects, we suggest that the EU amends this part of the guideline.

\section{Authors' affiliations}

P Knapp, D K Raynor, Pharmacy Practice and Medicines Management Group, University of Leeds, Leeds LS2 9JT, UK

D C Berry, Pro-Vice Chancellor's Office, University of Reading, Reading RG6 6AL, UK 


\section{Key messages}

- Patients want and need information about the side effects of medicines, but information on the level of risk of side effects is generally not provided.

- This study shows that the use of verbal descriptors leads to gross overestimation of the risk of side effects in people taking medicines. They are less satisfied with the information given, perceive a greater risk to health, and there may be some effect on decisions as to whether or not to take a medicine.

- Developing a language of risk which takes account of the various perspectives and contexts remains a challenge.

- In the meantime, verbal descriptors should not be used to describe the level of risk of side effects of medicines.

\section{REFERENCES}

1 Berry DC, Michas IC, Gillie T, et al. What do patients want to know about their medicines and what do doctors want to tell them? A comparative study. Psychol Health 1997; 12:467-80.

2 Berry DC, Michas IC, Bersellini E. Communicating information about medication side effects: effects on satisfaction, perceived risk to health and intention to comply. Psychol Health 2002;17:247-67.

3 Jones G. Prescribing and taking medicines. BMJ 2003;327:819-20.

4 Department of Health. National plan for the NHS. London: Department of Health, 2000.

5 European Commission. European Commission Council Directive 92/27/EEC (OJ NoL 113 of 30.4 .1992$, p.8) $\mathrm{m} 1992$.

6 European Commission. A guideline on the readability of the label and package leaflet of medicinal products for human use. EC Pharmaceuticals Committee, 1998.

7 Calman KC. Cancer, science and society and the communication of risk. BMJ 1996;313:799-802.
8 Bryant GD, Norman GR. Expressions of probability: words and numbers (letter). N Engl J Med 1980;302:41 1.

9 Timmermans D. The roles of experience and domain of expertise in using numerical and verbal probability: implications for securing informed consent to medical interventions. Med Decis Making 1994;14:146-56.

10 Berry DC, Knapp P, Raynor DK. Provision of information about drug side effects to patients. Lancet 2002;359:853-4.

11 Berry DC, Raynor DK, Knapp P, et al. Patients' understanding of risk associated with medication use. Drug Safety 2003;26:1-11.

12 Lloyd AJ. The extent of patients understanding of the risk of treatments. Qual Health Care 2001;10:i4-18.

13 Pedersen TR, Berg K, Cook TJ. Safety and tolerability of cholesterol lowering with simvastatin during 5 years in the Scandinavian Simvastatin Survival Study. Arch Intern Med 1996;156:2085-92.

14 Black DM, Bakker-Arkema RG, Nawrocki JW. An overview of the clinical safety profile of atorvastatin (lipitor), a new HMG-CoA reductase inhibitor. Arch Intern Med 1998;158:577-84.

15 Pander Maat $\mathbf{H}$, Klaasan R. Side effects of side effect information in drug information leaflets. J Tech Writ Commun 1994;24:389-404.

16 Fischer K, Jungermann $\mathrm{H}$. Rarely occurring headaches and rarely occurring blindness: is rarely necessary? J Behav Decis Making 1996;9:153-72.

17 Berry DC, Raynor DK, Knapp P. Communicating risk of medication side effects: an empirical evaluation of EU recommended terminology. Psychol Health Med 2003;8:251-63.

18 Dudley N. Importance of risk communication and decision making in cardiovascular conditions in older patients: a discussion paper. Qual Health Care 2001; 10:i19-22.

19 Edwards A, Elwyn GJ. Explaining risks: turning numerical data into meaningful pictures. BMJ 2002;324:827-30

20 Windschitl PD, Wells GL. Measuring psychological uncertainty: verbal versus numeric methods. J Exp Psychol Appl 1996;2:343-64.

21 Berry DC. Interpreting information about medicine side effects: differences in perception and intention to comply when medicines are prescribed for adults or young children. Psychol Health Med 2004 (in press).

22 Paling J. Strategies to help patients understand risks. BMJ 2003:327:745-8.

23 Edwards A, Elwyn G. Understanding risk and lessons for clinical risk communication about treatment preferences. Qual Health Care $2001 ; 10: 19-13$

24 Berry DC, Raynor DK, Knapp P, et al. Official warnings on thromboembolism risk with oral contraceptives fail to inform users adequately. Contraception 2002;66:305-7.

25 Calman K, Royston G. Risk language and dialects. BMJ 1997;315:939-42.

26 Calman K. Issues of risk: this unique opportunity. Br J Gen Pract $2001 ; 52: 47-51$. 